\title{
Enhanced UV protection and water adsorption properties of transparent poly(methyl methacrylate) films through incorporation of amorphous magnesium carbonate nanoparticles
}

\author{
Jiaojiao Yang ${ }^{1} \cdot$ Junxin Wang ${ }^{2} \cdot$ Maria Strømme $^{1} \mathbb{D} \cdot$ Ken Welch $^{1} \mathbb{D}$
}

Received: 7 January 2021 / Accepted: 21 June 2021 / Published online: 6 July 2021

(c) The Author(s) 2021

\begin{abstract}
A simple solution casting approach was used to obtain transparent and flexible poly(methyl methacrylate) (PMMA) films incorporated with $1-4 \%$ by weight amorphous magnesium carbonate nanoparticles. Optical transparency was retained in visible wavelengths, while transmittance in the UV-B region was reduced by $22 \%$ at $310 \mathrm{~nm}$ and $58 \%$ at $256 \mathrm{~nm}$ with the addition of $4 \mathrm{wt}$. \% nanoparticles. Furthermore, the incorporation of the nanoparticles was shown to provide protection for the films under UV-C irradiation ( $254 \mathrm{~nm}$ wavelength, $5 \mathrm{~mW} \mathrm{~cm}{ }^{-2}$ ), with the amount of UV degradation decreasing with increasing concentration of nanoparticles. Films with incorporated nanoparticles were also shown to be able to retain adsorbed moisture much better than neat PMMA films; whereas neat PMMA films did not retain moisture, approximately $50 \%$ of the adsorbed moisture was retained in films containing $4 \mathrm{wt}$. \% nanoparticles. These enhanced properties of PMMA are of great interest in applications such as flexible and transparent screens for personal electronic devices that require protection from both UV light and moisture.
\end{abstract}

Keywords Magnesium carbonate · Nanoparticles · Poly (methyl methacrylate) $\cdot$ UV protection $\cdot$ Water adsorption · Moisture barrier

\section{Introduction}

The displays of electronic devices such as cellular telephones and portable computers have traditionally been manufactured with rigid components such as liquid crystal displays (LCDs). Glass or thick plastic display covers are well suited for this purpose as they provide protection for the underlying sensitive electronic components from both mechanical and moisture damage. In recent years, however, flexible electronic technologies have attracted enormous interest, but also present technical challenges for protecting the devices from damage [1]. Among flexible display technologies, organic light-emitting diodes (OLEDs) have shown

Ken Welch

ken.welch@angstrom.uu.se

1 Division of Nanotechnology and Functional Materials, Department of Materials Science and Engineering, Uppsala University, 75121 Uppsala, Sweden

2 Division of Solid State Physics, Department of Materials Science and Engineering, Uppsala University, 7510375121 Uppsala, Sweden great potential in the "non-flat" environment, especially in the area of wearable electronic devices [2].

Electronic displays used in wearable devices are often exposed to relatively harsh and dynamic environments. Although flexible electronic display technologies may have some advantages over brittle, rigid glass displays in terms of impact resistance, they have increased sensitivity to damage caused by other sources, such as UV exposure and moisture. Light at UV wavelengths has higher energy than at visible wavelengths and can readily damage polymer components in flexible displays, resulting in changes in color (yellowing), increased brittleness or decreased flexibility [3, 4]. Light in UV-B (280-315 nm wavelengths) and UV-C (100-280 nm wavelengths) ranges generally cause more serious damage than that in the UV-A range (315-400 $\mathrm{nm}$ wavelengths) due to their higher energy and are therefore more critical to provide protection against. Moisture damage is another concern for flexible displays constructed from polymeric materials as it can result in changes in the flexibility of polymers and the reduction of transparency through damage of the molecular structure $[5,6]$. In some cases moisture may induce polymer chain crystallization or degradation $[7,8]$. It has also 
been observed that properties such as the refractive index of the material can be affected by the adsorption of water [9]. Furthermore, moisture that is absorbed in thin transparent screens can damage internal electronic components if this moisture permeates through the screen. Therefore, the development of novel materials for flexible displays with high transparency, UV-shielding properties and moisture resistance is very important for tomorrow's electronic devices.

Combining the mechanical flexibility of polymers and the tailored properties of inorganic nanoscale fillers is a promising solution to the demanding requirements of tomorrow's flexible displays [10-12]. For example, inorganic nanoscale particles of particular composition, size and crystallinity have the ability to provide UV-shielding without reducing transparency in the visible spectrum due their ability to only absorb photons with energy greater than the band gap of the particles. A wide range of inorganic nanoscale particles, including titanium dioxide, zinc oxide and calcium carbonate have been reported to enhance the UV-shielding properties of polymeric materials [13-15]. The degradation of polymers is also related to movements of the polymer chain and/or the breakage of chemical bonds. When dispersed in a polymeric matrix, inorganic nanoparticles can reduce the mobility of the polymer chain, and thereby increase the stability of the polymer $[16,17]$. Finally, nanoparticles have been shown capable of increasing the moisture resistance ability of polymer materials [18].

The method used to introduce inorganic nanoparticles into a polymer matrix can greatly affect the properties of nanocomposite. If nanoparticles form large aggregates in the polymer, the transparency of the nanocomposite material will be reduced because these aggregated nanoparticles 'lose' their nanosize and thus scatter a greater proportion of the light transmitted through the nanocomposite [19]. In situ synthesis of nanoparticles in the nanocomposite can result in highly homogeneous nanocomposites, but requires rigorous control of both the synthesis process of nanoparticles and the polymerization of the polymer matrix in the same reaction media [20]. Ex-situ methods offer the advantage of being able to combine a larger variety of inorganic fillers and polymer matrixes, but often result in inhomogeneous materials due to nanoparticle aggregation [21]. Casting a homogeneous solution containing surfactant-modified nanofillers and polymers offers the possibility to produce a homogeneous dispersion of nanofillers via a simple and inexpensive processing method [14, 22-24].

In the present study we present the fabrication of a novel nanoparticle-polymer nanocomposite thin film with UV-shielding properties that also has the ability to absorb and retain moisture. Magnesium carbonate was selected as the inorganic filler material as it is not only a designated generally recognized as safe (GRAS) material by the U.S. FDA, but it is also well known for its moisture absorbing properties, for example in applications such as climbing or gymnastics chalk. Furthermore, high surface area, amorphous magnesium carbonate nanoparticles (AMN) have been produced via a low temperature synthesis route, and have shown great promise for applications in drug delivery [25] and as an adhesive [26]. In the present study we utilize AMN in an optical application where AMN is used as a nanofiller in a polymer matrix of poly(methyl methacrylate) (PMMA). PMMA is a transparent (in the visible range) and flexible plastic with an extremely broad range of applications. Stearic acid was employed as a dispersant agent for AMN in a solution cast method to form the resulting AMNPMMA thin films.

\section{Materials and methods}

\section{Materials}

Magnesium oxide (MgO, 99.99\%), stearic acid (98.5\%), poly(methyl methacrylate) (PMMA, analytical standard, $\mathrm{M}_{\mathrm{w}}$ 350,000) and ethyl acetate (EtAc, 99.8\%) were obtained from Sigma-Aldrich, Sweden. Methanol $\left(\mathrm{CH}_{3} \mathrm{OH}, 99.9 \%\right)$ was purchased from VWR International. Carbon dioxide $\left(\mathrm{CO}_{2}\right)$ was provided by AirLiquide, Sweden. All reagents and solvents were used as received if not specially mentioned.

\section{Synthesis of amorphous magnesium carbonate nanoparticles (AMN)}

The synthesis of AMN was based on a previously reported procedure [25, 27]. Specifically, $4 \mathrm{~g} \mathrm{MgO}$ were dispersed in $60 \mathrm{~mL}$ methanol and placed under 4 bar $\mathrm{CO}_{2}$ pressure with rigorous stirring for 4 days at room temperature. After the pressure was released, $5 \mathrm{~mL}$ of the product from the reaction was added dropwise to $250 \mathrm{~mL}$ EtAc under stirring during which magnesium carbonate nanoparticles were formed. The obtained suspension was dried at $25^{\circ} \mathrm{C}$. The prepared materials were calcined at $250{ }^{\circ} \mathrm{C}$ with a temperature ramp of $1{ }^{\circ} \mathrm{C} \mathrm{min}-1$ and a hold time of $30 \mathrm{~min}$ to remove residual organic materials from the synthesis. The obtained materials were ground using a mortar to reduce particle agglomeration and achieve a free-flowing powder of AMN.

\section{Preparation of AMN-PMMA nanocomposite films}

$50 \mathrm{mg}$ AMN were dispersed in a solution of $15 \mathrm{~mL}$ acetone and $25 \mathrm{mg}$ stearic acid, and the suspension was sonicated for $30 \mathrm{~min}$ in a sealed bottle to obtain suspension A. $1 \mathrm{~g}$ PMMA was dissolved in $20 \mathrm{~mL}$ of acetone, and the solution was stirred for 30 min to obtain solution B. A specific amount of suspension A was added dropwise into solution 
B to achieve an AMN concentration corresponding to 1, 2 or $4 \%$ of the total mass of PMMA, AMN and stearic acid. The container was covered to reduce evaporation of acetone and the resulting suspension was stirred $2 \mathrm{~h}$ to ensure a homogenous dispersion of nanoparticles and then cast into a petri dish. The acetone was allowed to evaporate at room temperature and a relative humidity of $40 \%$ to obtain a $260 \mu \mathrm{m}$ thick AMN-PMMA composite film. A neat PMMA (i.e., 0 wt. \% AMN) film was also prepared without the addition of suspension A. Figure 1 presents a schematic representation of the procedures for AMN synthesis and preparation of AMN-PMMA films.

\section{Characterization}

A Merlin scanning electron microscope (Zeiss) was used to characterize the morphologies of the AMN and AMNPMMA films. AMN were dispersed in ethanol and sonicated $20 \mathrm{~min}$. A drop of the suspension was then placed on a silicon wafer and allowed to air dry. AMN-PMMA films were placed directly on a conductive carbon film. All samples were sputtered with a thin $\mathrm{Au} / \mathrm{Pd}$ coating prior to imaging to reduce charging effects and images were recorded with an acceleration voltage of $2 \mathrm{kV}$ using the in-lens detector.

A Bruker IFS 66v/S spectrometer was used for FTIR measurements of neat PMMA and AMN-PMMA films. The resolution was $4 \mathrm{~cm}^{-1}$ and the spectrum was collected from 400 to $4000 \mathrm{~cm}^{-1}$. Background removal was carried out prior to analysis.

XRD measurements were carried out with a Bruker D8 TwinTwin instrument with $\mathrm{Cu}-\mathrm{K} \alpha$ irradiation $(40 \mathrm{kV}$,
$40 \mathrm{~mA}$ ). The AMN sample was ground to a fine powder prior to analysis. AMN-PMMA films were placed directly on a silicon holder. Diffraction patterns were collected in

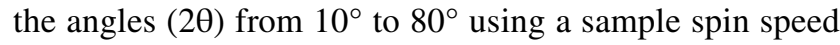
of $80 \mathrm{rpm}$.

TGA studies were performed using a Mettler Toledo TGA/DSC 3 + instrument. Each sample of approximately $15 \mathrm{mg}$ was placed in an alumina crucible under airflow $\left(45 \mathrm{~mL} \mathrm{~min}^{-1}\right)$. The mass of the sample was recorded as the temperature was increased from $25^{\circ} \mathrm{C}$ to $600{ }^{\circ} \mathrm{C}$ at $3{ }^{\circ} \mathrm{C} \min ^{-1}$.

A TA DSC Q2000 instrument was used for DSC measurements. Each sample of approximately $5 \mathrm{mg}$ was placed in an aluminum pan with a lid. The heat flow was recorded during the temperature scan from $-50{ }^{\circ} \mathrm{C}$ to $300{ }^{\circ} \mathrm{C}$ at $3{ }^{\circ} \mathrm{C} \mathrm{min}-1$ in a $\mathrm{N}_{2}$ atmosphere.

For suspensions of AMN in ethanol, a transmittance spectrum was measured by a Shimadzu 1650PC UV-Vis spectrophotometer. For AMN-PMMA nanocomposite films, the transmittance spectra were measured by a Perkin-Elmer Lambda 900 spectrophotometer with a $150 \mathrm{~nm}$ Spectraloncoated integrating sphere. Measurements were carried out from 200 to $800 \mathrm{~nm}$ at a scan speed of $237 \mathrm{~nm} \mathrm{~min}{ }^{-1}$ with a slit width of $3 \mathrm{~nm}$. The deuterium lamp was utilized from 200 to $300 \mathrm{~nm}$ while the halogen lamp was utilized from 300 to $800 \mathrm{~nm}$.

\section{Moisture adsorption and desorption of films}

Each film was weighed before being stored in a desiccator at $25{ }^{\circ} \mathrm{C}$ and $75 \%$ relative humidity (RH). After $24 \mathrm{~h}$ the
Fig. 1 Schematic representation of the procedures for AMN synthesis and preparation of AMN-PMMA films
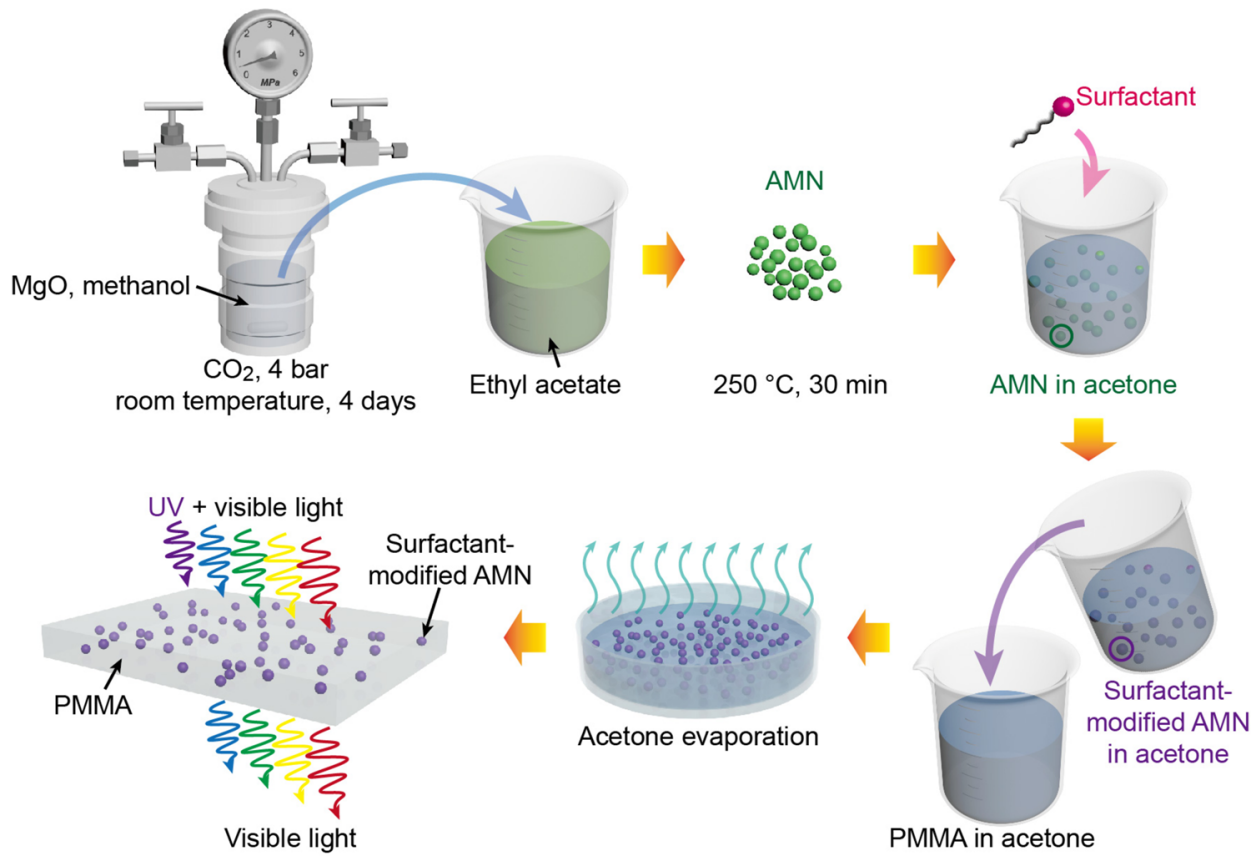
films were weighed again to check for moisture adsorption and then placed in another desiccator at $75^{\circ} \mathrm{C}$ and $75 \% \mathrm{RH}$. After $24 \mathrm{~h}$ the films were weighed again to determine the amount of moisture desorbed. AMN-PMMA films at each concentration of AMN were tested in triplicate.

\section{UV degradation of films}

After the moisture adsorption and desorption study the nanocomposite films were dried in vacuum for $24 \mathrm{~h}$ and then irradiated with a UV-C lamp (Philips TUV PL-S $11 \mathrm{~W} / 2 \mathrm{P}$, wavelength of $254 \mathrm{~nm}$, intensity $=5 \mathrm{~mW} \mathrm{~cm}^{-2}$ ) for 1,3 and $6 \mathrm{~h}$. Transmittance spectra of the films were recorded with a UV-Vis spectrophotometer (1650PC, Shimadzu) before and after each exposure interval.

(a)

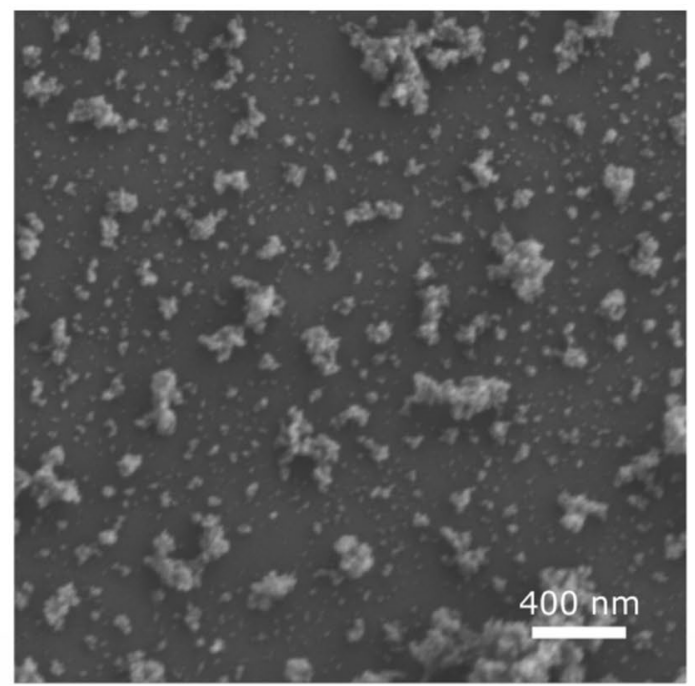

(c)

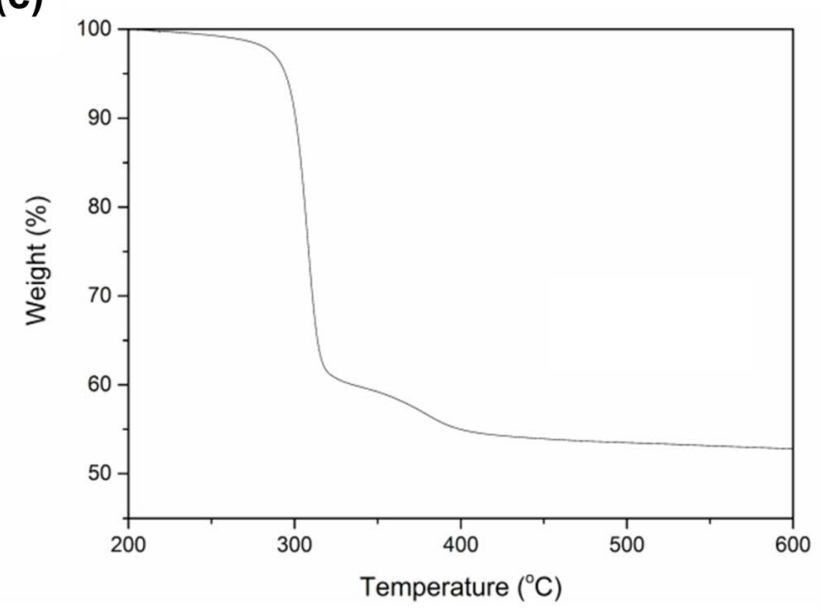

\section{Results and discussion}

Characterization of the AMN is presented in Fig. 2. While individual nanoparticles on the order of $50 \mathrm{~nm}$ in diameter or less can be discerned, most appear in larger aggregates in the SEM image (Fig. 2a). The XRD pattern (Fig. 2b) shows two halo peaks between $12^{\circ}$ and $40^{\circ}$, indicating a primarily amorphous material, with small, sharp peaks at $29^{\circ}$ and $42^{\circ}$ that correspond to unreacted crystalline $\mathrm{MgO}$ [27]. Figure $2 \mathrm{c}$ shows the TGA trace of the AMN sample where we can observe magnesium carbonate decomposing at $\sim 300-325^{\circ} \mathrm{C}$, which corresponds to previous reports $[25,27]$. At even higher temperatures only $\mathrm{MgO}$ remains from the sample, and from calculations based on the stoichiometry of $\mathrm{MgCO}_{3}$ and the relative mass contribution of $\mathrm{MgO}$ we can calculate that the mass of unreacted $\mathrm{MgO}$ in the

(b)

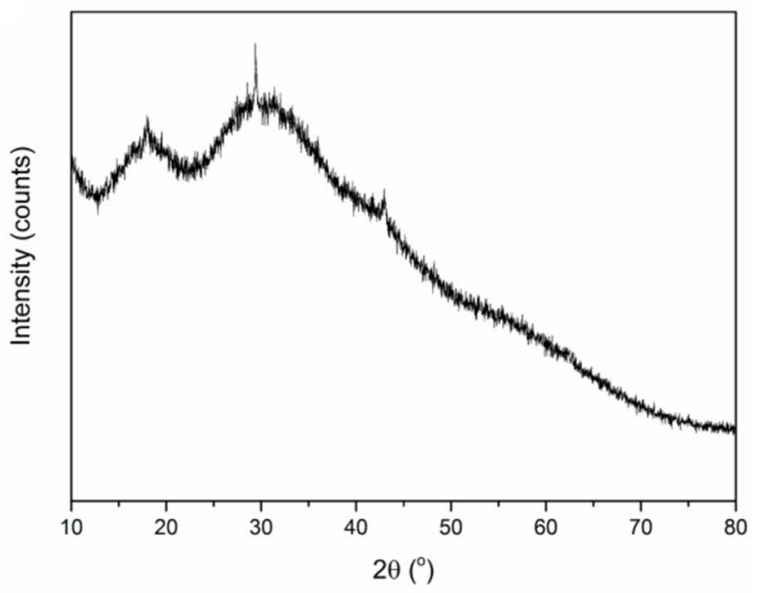

(d)

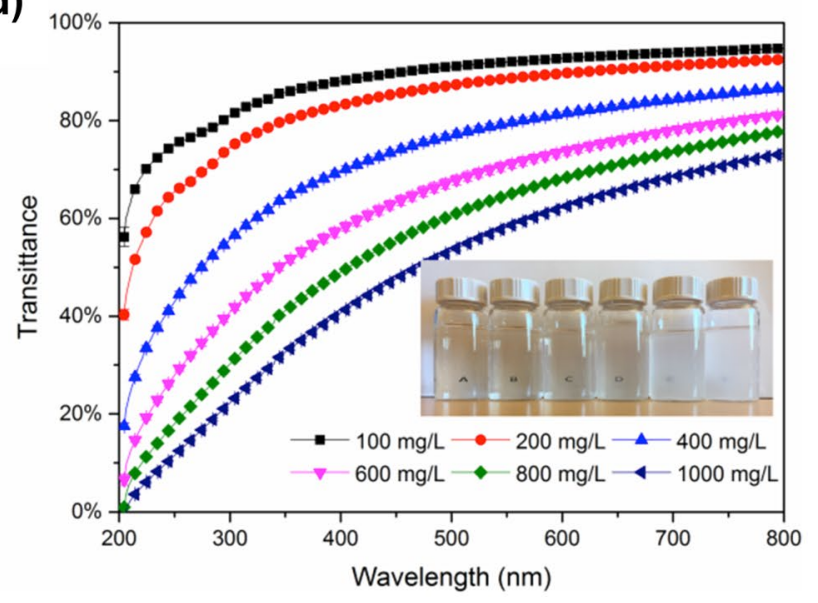

Fig. 2 (a) Scanning electron microscopy image, (b) X-ray diffraction pattern and (c) normalized mass thermogravimetric analysis curve of the as-prepared AMN. (d) UV-Vis absorption of the as-prepared AMN in ethanol at different concentrations 


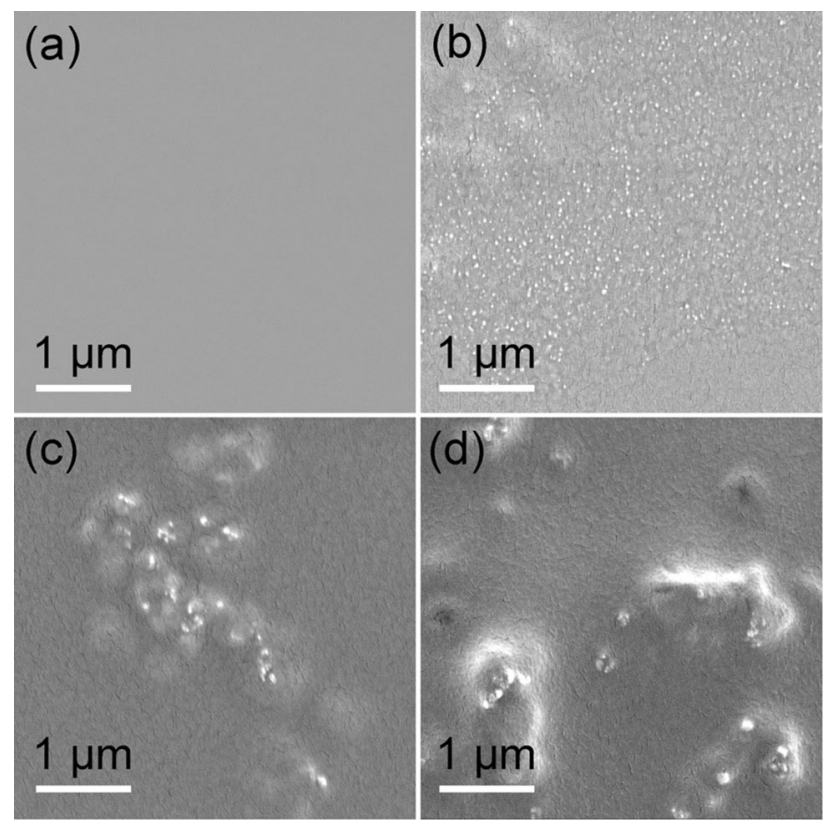

Fig. 3 Scanning electron microscopy images for AMN-PMMA films. The mass ratios of AMN to PMMA are (a) 0 wt. \%, (b) 1 wt. \%, (c) 2 wt. $\%$ and (d) 4 wt. \%

sample is between 12 and $15 \%$ [27], which means that the yield of AMN from the synthesis is approximately $85-88 \%$. Figure $2 \mathrm{~d}$ presents the transmittance of AMN suspensions in ethanol at concentrations ranging from 100 to $1000 \mathrm{mg}$ $\mathrm{L}^{-1}$ where it can be observed that absorption is greater at shorter wavelengths. The insert to Fig. $2 d$ shows that in the visible region, transmittance decreases markedly at concentrations above $600 \mathrm{mg} \mathrm{L}^{-1}$ (i.e., the letters "E" and "F" are difficult to discern through the suspensions in the rightmost two vials containing AMN suspensions of 800 and $1000 \mathrm{mg}$ $\mathrm{L}^{-1}$, respectively).

The surface morphologies of prepared AMN-PMMA films were characterized by SEM (Fig. 3). While the neat PMMA film appears featureless (Fig. 3a), nanoparticles can be clearly observed at the surface of films containing AMN (Fig. 3b-d). These nanoparticles were much more evenly dispersed at the surface of the $1 \mathrm{wt}$. \% film compared to the 2 wt. $\%$ and 4 wt. $\%$ films, where the nanoparticles appear to have collected in aggregates. Furthermore, larger aggregates were observed with the 4 wt. \% film compared to the $2 \mathrm{wt}$. $\%$ film. FTIR measurements of the AMN-PMMA films were identical to that of the neat PMMA film, which indicated that the nanoparticles or aggregates of nanoparticles were encased in PMMA and not exposed at the surface (data not shown).

Figure 4a displays the XRD patterns of the prepared PMMA and AMN-PMMA films, which show that the films remain amorphous after the addition of AMN. The halo peak around $30^{\circ}$ in the neat PMMA film increases in the AMNPMMA films with an increase in AMN content, which can be attributed to the corresponding halo peak for AMN at approximately $30^{\circ}$ (see Fig. 2b). As well, no sharp peaks corresponding to crystalline stearic acid (c.f. Fig. 4b) are visible in the AMN-PMMA films, which indicates that stearic acid did not precipitate out of the mixture and crystalize, and thus was well distributed in the nanocomposite films, which likely aided in dispersing the nanoparticles.

Figure 5 displays the results of the thermal analyses of the films where it can be seen that the incorporation of nanoparticles results in an increase in thermal stability of the PMMA
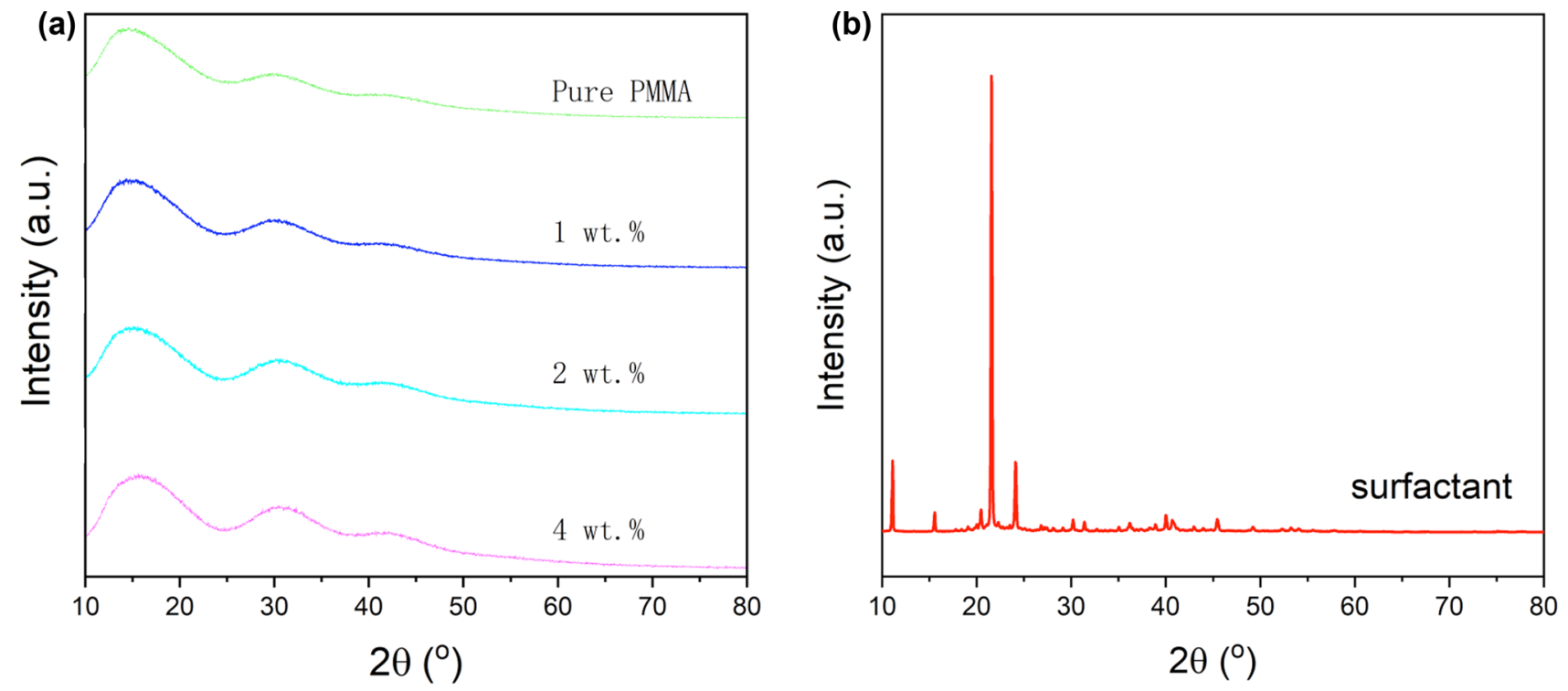

Fig. 4 X-Ray diffraction patterns for (a) neat PMMA and AMN-PMMA nanocomposite films and (b) the powder of stearic acid surfactant 

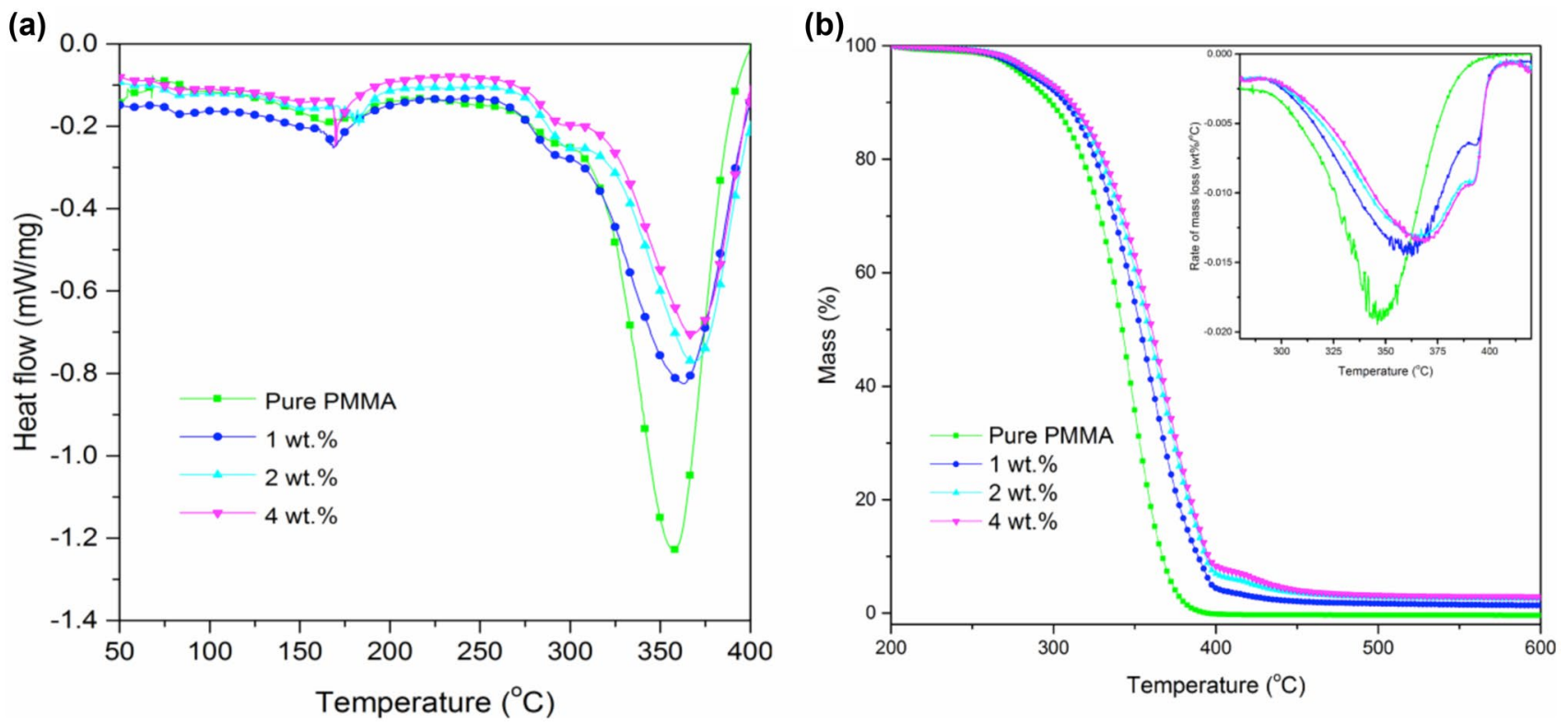

Fig. 5 (a) Differential scanning calorimetry traces for neat PMMA and AMN-PMMA films. (b) Normalized mass thermogravimetric analysis traces for neat PMMA and AMN-PMMA nanocomposite films. Insert shows the rate of weight loss of films during the heating process

films. Table 1 displays a summary of the thermal decomposition temperatures of the different films as measured by both DSC and TGA. In Fig. 5a, the DSC traces show that the endothermic peak at $357^{\circ} \mathrm{C}$ for the neat PMMA sample, corresponding to the final degradation of the polymer, increased between 5 and $10{ }^{\circ} \mathrm{C}$ with the incorporation of AMN, while the corresponding TGA curves show that the decomposition temperature increased by 15 to $20^{\circ} \mathrm{C}$ (see insert to Fig. 5b). These results are supported by previous reports of enhanced thermal stability of PMMA due to incorporated inorganic nanoparticles [28-30]. Note that the small endothermic peaks at approximately $160{ }^{\circ} \mathrm{C}$ in the DSC traces correspond to the glass transition of PMMA [30].

Transparency of the AMN-PMMA films is shown in Fig. 6, where it can be seen that the addition of AMN is not detectible with the unaided eye with 1 or 2 wt. \% AMN. At 4 wt. \% AMN a very slight decrease in transparency is noticeable, which may be due to the larger aggregates of AMN that form (c.f. Fig. 3). This decrease in transparency can be expected from the larger particle aggregates in the film due to Mie scattering. However, even at 4 wt. \% the flexibility of the film is maintained as shown by the insert in Fig. 6 .

Table 1 Thermal decomposition temperatures of AMN-PMMA films

\begin{tabular}{lllll}
\hline $\begin{array}{l}\text { Measurement } \\
\text { technique }\end{array}$ & neat PMMA & 1 wt. $\%$ & 2 wt. $\%$ & 4 wt. $\%$ \\
\hline DSC & $357{ }^{\circ} \mathrm{C}$ & $362{ }^{\circ} \mathrm{C}$ & $365{ }^{\circ} \mathrm{C}$ & $367{ }^{\circ} \mathrm{C}$ \\
TGA & $348^{\circ} \mathrm{C}$ & $352{ }^{\circ} \mathrm{C}$ & $365^{\circ} \mathrm{C}$ & $369{ }^{\circ} \mathrm{C}$ \\
\hline
\end{tabular}

The UV-shielding properties of the AMN-PMMA films are displayed in Fig. 7. In the visible region, these composite films were transparent with transmittances close to that of the neat PMMA film, except for the $4 \mathrm{wt}$. \% film (Fig. 7a), which showed a larger decrease in transmittance for visible wavelengths, corresponding to the slightly detectible decrease in transparency shown in Fig. 6. However, at UV-B and UV-C wavelengths, transmittance decreased as a function of AMN concentration in the film. For example, at

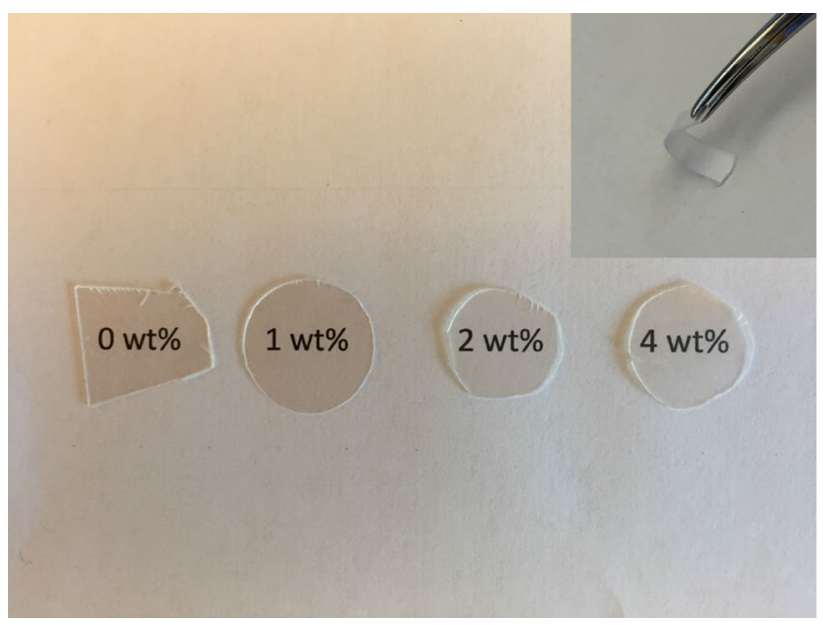

Fig. 6 Optical photographs of AMN-PMMA films placed on a sheet of paper with printed text corresponding to the wt\% AMN. Visibility of the text through the films indicates the apparent transparency. Insert shows that the AMN-PMMA film with 4 wt. \% AMN retains flexibility 

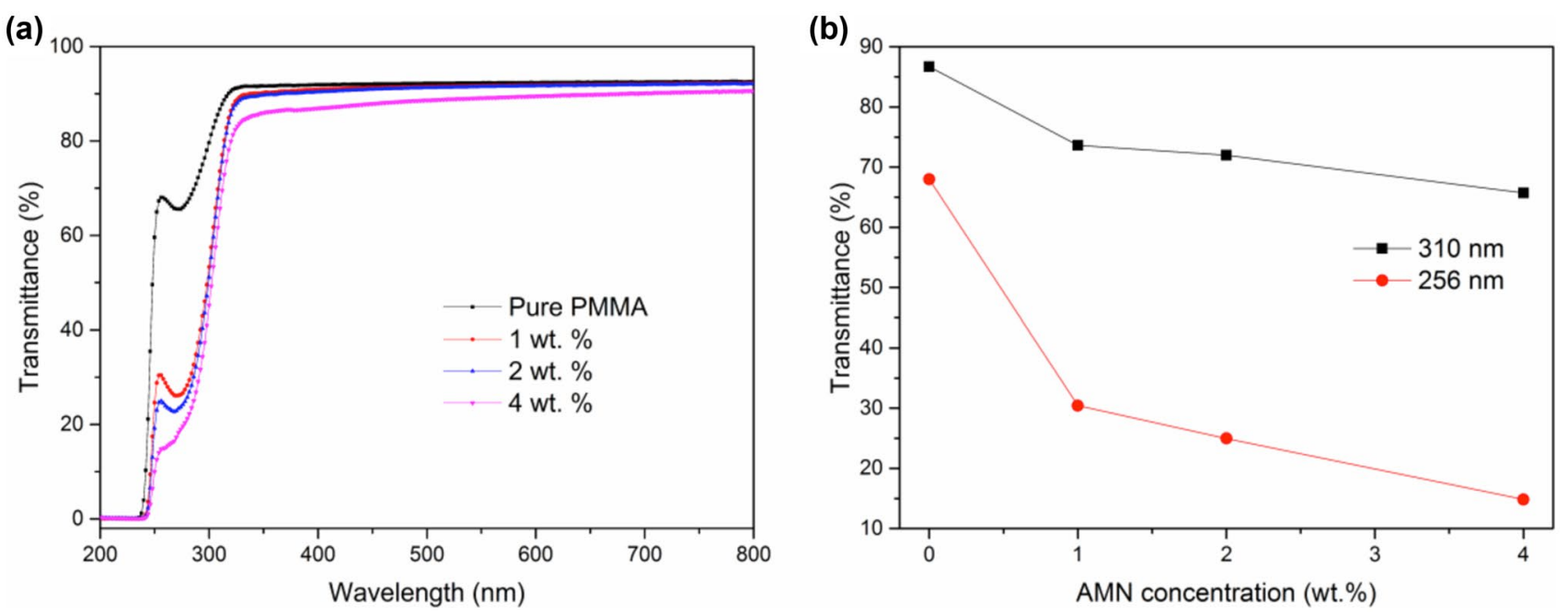

Fig. 7 (a) UV-Vis transmittance spectra of the investigated films. (b) Transmittances for $310 \mathrm{~nm}$ and $256 \mathrm{~nm}$ UV irradiations of the investigated films

$310 \mathrm{~nm}$, transmittances of the films containing $0 \mathrm{wt} . \%, 1$ wt. $\%, 2$ wt. $\%$ and 4 wt. $\%$ AMN were $87 \%, 73 \%, 71 \%$ and $66 \%$, respectively, whereas for $256 \mathrm{~nm}$ the corresponding transmittances were $68 \%, 30 \%, 25 \%$ and $15 \%$, respectively (Fig. 7b). The UV-shielding abilities of these composite films were greater than what was expected from the addition of the nanoparticles when comparing the adsorption of the nanoparticles alone at wavelengths less than $320 \mathrm{~nm}$ (see Fig. 2d). A previous study of $\mathrm{ZnO}$ nanoparticles dispersed in PMMA films attributed similar effects to the quantum coupling of exciton states in closely spaced quantum dots [31]. As well, the addition of surfactants is not expected to affect the transmission of UV light [14].

The water absorption and desorption properties of these films were also studied by first placing the films in a humid environment at $25{ }^{\circ} \mathrm{C}$ with $75 \% \mathrm{RH}$ for $24 \mathrm{~h}$ to determine the amount of moisture absorbed. The temperature was subsequently increased to $75^{\circ} \mathrm{C}$ for $24 \mathrm{~h}$ at $75 \% \mathrm{RH}$ to study how much of the absorbed moisture would be retained in the films. The results are shown in Table 2 and show that the addition of 4 wt. \% AMN increased the amount of moisture absorbed by $29 \%$ compared to the neat PMMA film, which showed a weight increase of $1.65 \%$ after $24 \mathrm{~h}$ at $75 \% \mathrm{RH}$ and $25^{\circ} \mathrm{C}$. Interestingly, when the temperature was increased to $75^{\circ} \mathrm{C}$, the neat PMMA film released nearly all the absorbed moisture (less than $1 \%$ of the absorbed water was retained), whereas almost half of the absorbed water was retained in the AMN-PMMA composite film with 4 wt. $\%$ AMN. The results can be attributed to the absorbance ability of AMN, as described in our previous report [27]. The ability of a material to retain absorbed moisture is of particular importance in applications such as thin, flexible screens that act as moisture barriers to protect sensitive electronic components that are easily damaged by moisture, such as OLEDs. If the absorbed moisture is retained in the barrier instead of being transmitted through the barrier, the lifetime of such devices can be significantly extended.

Finally, the ability of the incorporated AMN to protect the film from UV degradation was studied by irradiating the films with UV-C light, and the results are shown in Fig. 8. After $1 \mathrm{~h}$ of UV treatment the degradation of the neat PMMA film is seen as a significant decrease in transmittance of light at wavelengths of approximately $450 \mathrm{~nm}$ and lower. This manifests itself as a slight yellowing of the
Table 2 Absorbed and retained moisture in neat PMMA and AMN-PMMA films

\begin{tabular}{llccc}
\hline & 0 & 1 wt. \% & 2 wt. \% & 4 wt. \% \\
\hline $\begin{array}{l}\text { Percentage of water absorbed } \\
\text { at } 25^{\circ} \mathrm{C}, 75 \% \mathrm{RH}^{\mathrm{a}}\end{array}$ & $1.6 \pm 0.1$ & $1.8 \pm 0.6$ & $2.1 \pm 0.5$ & $2.1 \pm 0.5$ \\
$\begin{array}{l}\text { Percentage of absorbed water retained after } \\
\text { temperature increase to } 75{ }^{\circ} \mathrm{C}, 75 \% \mathrm{RH}^{\mathrm{b}}\end{array}$ & $0.8 \pm 0.2$ & $19.8 \pm 0.7$ & $25.2 \pm 0.8$ & $48.0 \pm 0.8$ \\
\hline
\end{tabular}

${ }^{a}$ calculated by the weight change before and after absorption of water, divided by the weight of the film $\times 100 \%$

${ }^{b}$ calculated by the weight change before and after desorption at $75{ }^{\circ} \mathrm{C}$, divided by the weight change before and after absorption at $25^{\circ} \mathrm{C} \times 100 \%$ 
Fig. $8 \mathrm{UV}-$ Vis transmittance spectra after UV-C (254 nm) treatment for PMMA films containing (a) 0 wt. $\%$ AMN, (b) 1 wt. \% AMN, (c) 2 wt. \% AMN and (d) 4 wt. \% AMN
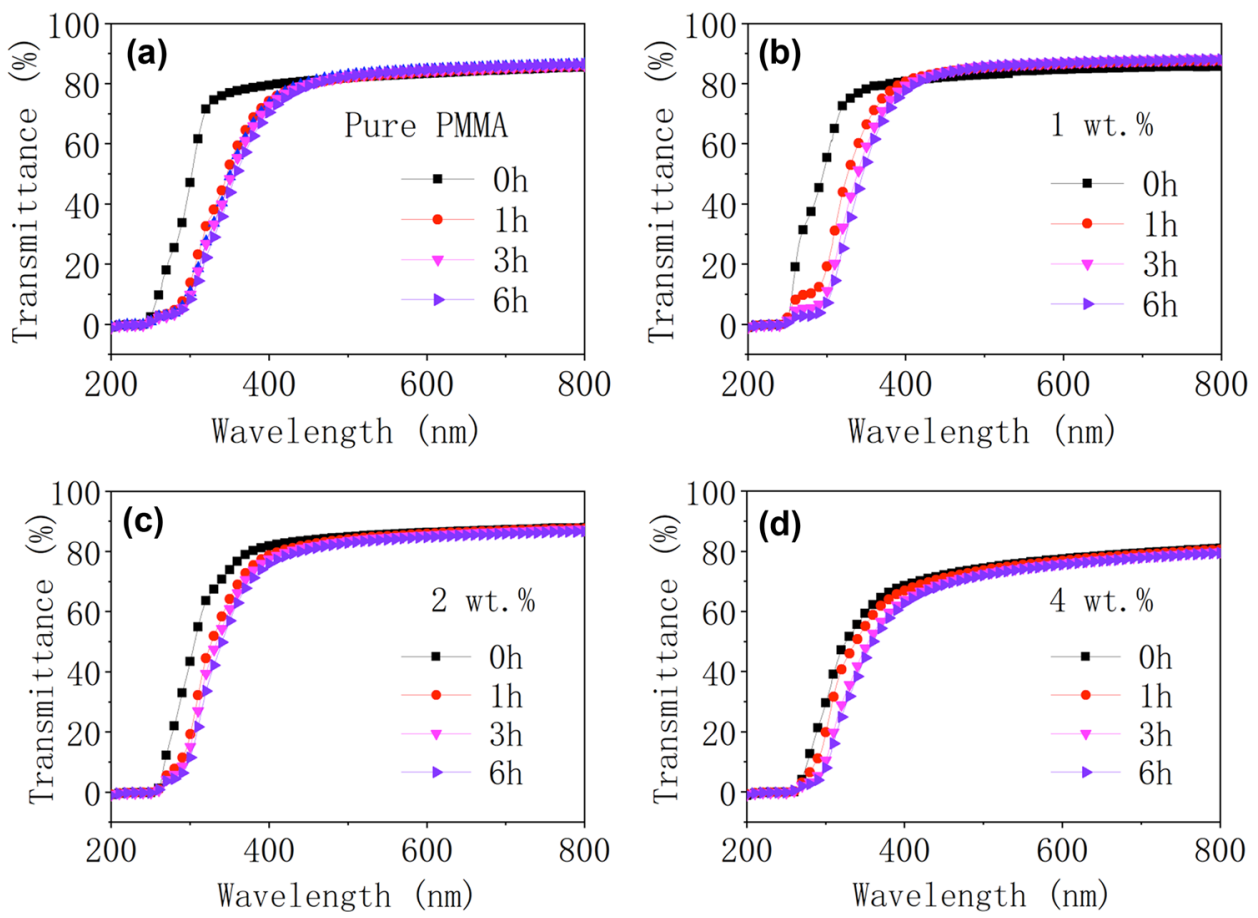

film upon visual inspection. From Fig. 8b-d it can been seen that increasing wt. \% of AMN reduces this degradation by both shifting the degradation to lower wavelengths and increasing the irradiation time to achieve equivalent degrees of degradation. The greatest protection is seen with 4 wt. \% AMN where very little degradation is seen after $1 \mathrm{~h}$ irradiation. After $6 \mathrm{~h}$ irradiation, significant degradation in the film is only observed for wavelengths less than $400 \mathrm{~nm}$, indicating that the visible properties of the film are unaffected.

\section{Conclusions}

A simple and effective solution casting method was employed to obtain AMN-PMMA nanocomposite films that possess desirable UV shielding/protection and moisture retention properties. Stearic acid was used as a surfactant to enhance dispersion of AMN in the PMMA matrix. The AMN-PMMA nanocomposite films with up to 4 wt. \% nanoparticles retained the functional properties of the neat PMMA films such as mechanical flexibility and transparency in the visible region, but showed efficient UV-shielding ability in the UV-B and UV-C regions. Additionally, the AMN-PMMA films can adsorb water in a high humidity environment, and retain this adsorbed water with increases in temperature, a property that should prove useful in applications such as barrier films in transparent, flexible electronic displays.
Acknowledgements We acknowledge the funding agency Vinnova and the China Scholarship Council for financial support of the presented work.

Authors' contributions J. Yang and K. Welch designed the project. J. Yang and J. Wang carried out experiments. J. Yang analyzed data and wrote the manuscript. M. Strømme and K. Welch revised the manuscript.

Funding Open access funding provided by Uppsala University. The work is supported by Vinnova and the China Scholarship Council.

Open Access This article is licensed under a Creative Commons Attribution 4.0 International License, which permits use, sharing, adaptation, distribution and reproduction in any medium or format, as long as you give appropriate credit to the original author(s) and the source, provide a link to the Creative Commons licence, and indicate if changes were made. The images or other third party material in this article are included in the article's Creative Commons licence, unless indicated otherwise in a credit line to the material. If material is not included in the article's Creative Commons licence and your intended use is not permitted by statutory regulation or exceeds the permitted use, you will need to obtain permission directly from the copyright holder. To view a copy of this licence, visit http://creativecommons.org/licenses/by/4.0/.

\section{References}

1. Eda G, Fanchini G, Chhowalla M (2008) Large-area ultrathin films of reduced graphene oxide as a transparent and flexible electronic material. Nat Nanotechnol 3:270-274. https://doi.org/10.1038/ nnano.2008.83

2. Han TH, Lee Y, Choi MR, Woo SH, Bae SH, Hong BH, Ahn JH, Lee TW (2012) Extremely efficient flexible organic light-emitting 
diodes with modified graphene anode. Nat Photonics 6:105-110. https://doi.org/10.1038/nphoton.2011.318

3. Gijsman P, Meijers G, Vitarelli G (1999) Comparison of the UVdegradation chemistry of polypropylene, polyethylene, polyamide 6 and polybutylene terephthalate. Polym Degrad Stabil 65:433441. https://doi.org/10.1016/S0141-3910(99)00033-6

4. Çaykara T, Güven O (1999) UV degradation of poly (methyl methacrylate) and its vinyltriethoxysilane containing copolymers. Polym Degrad Stabil 65:225-229. https://doi.org/10.1016/S01413910(99)00008-7

5. Azwa Z, Yousif B, Manalo A, Karunasena W (2013) A review on the degradability of polymeric composites based on natural fibres. Mater Design 47:424-442. https://doi.org/10.1016/j.matdes.2012. 11.025

6. Kumar R, Auch M, Ou E, Ewald G, Jin CS (2002) Low moisture permeation measurement through polymer substrates for organic light emitting devices. Thin Solid Films 417:120-126. https://doi. org/10.1016/S0040-6090(02)00584-9

7. Jabarin S (1987) Crystallization kinetics of poly (ethylene terephthalate). III. Effect of moisture on the crystallization behavior of PET from the glassy state. J Appl Polym Sci 34103-108. https:// doi.org/10.1002/app.1987.070340109

8. Marcovich NE, Reboredo MM, Aranguren MI (1998) Dependence of the mechanical properties of woodflour-polymer composites on the moisture content. J Appl Polym Sci 68:2069-2076. https:// doi.org/10.1002/(SICI)1097-4628(19980627)68:13\%3c2069:: AID-APP2\%3e3.0.CO;2-A

9. Jördens C, Wietzke S, Scheller M, Koch M (2010) Investigation of the water absorption in polyamide and wood plastic composite by terahertz time-domain spectroscopy. Polym Test 29:209-215. https://doi.org/10.1016/j.polymertesting.2009.11.003

10. Roy S, Kim H, Kim J, Zhai L, Zhu Q, Kim J (2020) Incorporation of melanin nanoparticles improves UV-shielding, mechanical and antioxidant properties of cellulose nanofiber based nanocomposite films. Mater Today Commun 24:100984. https://doi.org/10.1016/j. mtcomm.2020.100984

11. Gomez-Hermoso-de-Mendoza J, Gutierrez J, Tercjak A (2020) Transparent and flexible cellulose triacetate- $\mathrm{TiO}_{2}$ nanoparticles with conductive and UV-shielding properties. J Phys Chem C 12:4242-4251. https://doi.org/10.1021/acs.jpcc.9b11298

12. Liang F, Fan YJ, Kuang SY, Wang H, Wang Y, Xu P, Wang Z, Zhu G (2020) Layer-by-layer assembly of nanofiber/nanoparticle artificial skin for strain-insensitive UV shielding and visualized UV detection. Adv Mater Technol 5:1900976. https://doi.org/10. 1002/admt.201900976

13. Dawidczyk TJ, Walton MD, Jang WS, Grunlan JC (2008) Layer-bylayer assembly of UV-resistant poly (3, 4-ethylenedioxythiophene) thin films. Langmuir 24:8314-8318. https://doi.org/10.1021/la800967x

14. Tu Y, Zhou L, Jin YZ, Gao C, Ye ZZ, Yang YF, Wang QL (2010) Transparent and flexible thin films of ZnO-polystyrene nanocomposite for UV-shielding applications. J Mater Chem 20:15941599. https://doi.org/10.1039/B914156A

15. Pal MK, Singh B, Gautam J (2012) Thermal stability and UVshielding properties of polymethyl methacrylate and polystyrene modified with calcium carbonate nanoparticles. J Therm Anal Calorim 107:85-96. https://doi.org/10.1007/s10973-011-1686-3

16. Kumar AP, Depan D, Tomer NS, Singh RP (2009) Nanoscale particles for polymer degradation and stabilization-trends and future perspectives. Prog Polym Sci 34:479-515. https://doi.org/ 10.1016/j.progpolymsci.2009.01.002

17. Göpferich A (2006) Mechanisms of polymer degradation and erosion. The Biomaterials: Silver Jubilee Compendium, Elsevier, pp. 117-128. ISBN: 9780080528069
18. Matei A, Cernica I, Cadar O, Roman C, Schiopu V (2008) Synthesis and characterization of $\mathrm{ZnO}$-polymer nanocomposites. Int J Mater Form 1:767-770. https://doi.org/10.1007/ s12289-008-0288-5

19. Qiang X, Chunfang Z, JianZun Y, Yuan CS (2004) The effects of polymer-nanofiller interactions on the dynamical mechanical properties of $\mathrm{PMMA} / \mathrm{CaCO}_{3}$ composites prepared by microemulsion template. J Appl Polym Sci 91:2739-2749. https://doi.org/ 10.1002/app.13441

20. Li S, Toprak MS, Jo YS, Dobson J, Kim DK, Muhammed M (2007) Bulk synthesis of transparent and homogeneous polymeric hybrid materials with $\mathrm{ZnO}$ quantum dots and PMMA. Adv Mater 19:4347-4352. https://doi.org/10.1002/adma.200700736

21. Demir MM, Koynov K, Akbey Ü, Bubeck C, Park I, Lieberwirth I, Wegner G (2007) Optical properties of composites of PMMA and surface-modified zincite nanoparticles. Macromolecules 40:1089-1100. https://doi.org/10.1021/ma062184t

22. Contreras C, Weibel D, Strumia M (2021) Polystyrene brushes/ $\mathrm{TiO}_{2}$ nanoparticles prepared via SI-ATRP on polypropylene and its superhydrophobicity. J Polym Res 28:1-9. https://doi.org/10. 1007/s10965-021-02462-9

23. Su S, Lin F, Huang C, Lu C, Chen J (2019) Coordination between surface lattice resonances of poly (glycidyl methacrylate) line array and surface plasmon resonances of CdS quantum on silicon surface. Polymers 11:558. https://doi.org/10.3390/polym11030558

24. Tu C, Tsai F, Chang C, Yang C, Kuo S, Zhang J, Chen T, Huang C (2019) Surface-initiated initiators for continuous activator regeneration (SI ICAR) ATRP of MMA from 2, 2, 6, 6-tetramethylpiperidine-1-oxy (TEMPO) oxidized cellulose nanofibers for the preparations of PMMA nanocomposites. Polymers 11:1631. https://doi.org/10.3390/polym11101631

25. Yang J, Alvebratt C, Lu X, Bergström CA, Strømme M, Welch K (2018) Amorphous magnesium carbonate nanoparticles with strong stabilizing capability for amorphous ibuprofen. Int J Pharm 548:515-521. https://doi.org/10.1016/j.ijpharm.2018.07.021

26. Yang J, Chen S, Luo J, Persson C, Cölfen H, Welch K, Strømme M (2020) Multifunctional polymer-free mineral plastic adhesives formed by multiple noncovalent bonds. ACS Appl Mater Interfaces 12:7403-7410. https://doi.org/10.1021/acsami.9b17253

27. Yang J, Han Y, Luo J, Leifer K, Strømme M, Welch K (2019) Synthesis and characterization of amorphous magnesium carbonate nanoparticles. Mater Chem Phys 224:301-307. https://doi.org/ 10.1016/j.matchemphys.2018.12.037

28. Agrawal S, Patidar D, Saxena N (2011) Glass transition temperature and thermal stability of ZnS/PMMA nanocomposites. Phase Transit 84:888-900. https://doi.org/10.1080/01411594.2011.563152

29. Hammani S, Barhoum A, Bechelany M (2018) Fabrication of PMMA/ZnO nanocomposite: effect of high nanoparticles loading on the optical and thermal properties. J Mater Sci 53:1911-1921. https://doi.org/10.1007/s10853-017-1654-9

30. Dixit M, Gupta S, Mathur V, Rathore KS, Sharma K, Saxena N (2009) Study of glass transition temperature of PMMA and CdSPMMA composite. Chalcogenide Lett 6:131-136

31. Wong M, Guenther J, Sun L, Blümel J, Nishimura R, Sue HJ (2012) Synthesis and fabrication of multifunctional nanocomposites: stable dispersions of nanoparticles tethered with short, dense and polydisperse polymer brushes in poly (methyl methacrylate). Adv Funct Mater 22:3614-3624. https://doi.org/10.1002/adfm. 201200083

Publisher's Note Springer Nature remains neutral with regard to jurisdictional claims in published maps and institutional affiliations. 